\title{
Differential Regulation of Gene Expression in the Obligate Biotrophic Interaction of Uromyces fabae with Its Host Vicia faba
}

\author{
Stefan G. R. Wirsel, Ralf T. Voegele, and Kurt W. Mendgen \\ Lehrstuhl Phytopathologie, Fachbereich Biologie, Universität Konstanz, Universitätsstr. 10, 78457 \\ Konstanz, Germany \\ Submitted 19 March 2001; Accepted 18 July 2001.
}

Classical analysis of obligate biotrophic fungi revealed changes of enzyme activities or the concentration of metabolites in infected areas. However, due to the intricate integration of host and parasite metabolism, it was not possible to delineate the individual contributions of the two organisms. Here, we used reverse-transcription-polymerase chain reaction to monitor expression of genes from the rust fungus Uromyces fabae and its host Vicia faba. We focused on genes relevant for amino acid and sugar uptake and metabolism in both organisms. In the fungus, mRNA for plasma membrane ATPase was detected in spores and all infection structures. Two genes for fungal amino acid transporters showed dissimilar regulation. Transcripts for one were detected during all developmental stages, whereas those of the other appeared to be under developmental control. The latter result was also obtained for the so far only hexose transporter known from $U$. fabae and for one gene of the thiamine biosynthesis pathway. In the host plant, transcripts for two ATPases analyzed generally declined upon infection. Sucrose synthase expression increased in leaves, but decreased in roots. Transcript levels of glucose and sucrose transporter genes appeared unchanged. Markers for amino acid metabolism did not show a uniform trend: transcripts for asparagine synthetase increased, whereas those for two amino acid transporters either decreased or increased. Our analyses revealed that not only expression of genes in the immediate vicinity of the primary infection site is altered, but infection also influences transcription of certain genes in remote organs, like stems and roots. This demonstrates alterations in the source-sink relationships.

Rust fungi are obligate biotrophic plant pathogens belonging to the division Basidiomycota. Uromyces fabae exhibits an autoecious, macrocyclic life cycle on Vicia faba (broad bean). Experimentally, only uredospores are easily produced in larger quantities for use in infection studies and for in vitro differentiation experiments (Deising et al. 1991). The latter allow simulation of the early developmental program without interference by host factors.

We previously showed that $U$. fabae possesses a set of genes that is strongly induced during the stage of haustorial

Corresponding author: Stefan G. R. Wirsel; Telephone: +49 7531 882107; Fax: +49 7531 883035; E-mail: Stefan.Wirsel@uni-konstanz.de development, reflecting the adaptation to an altered environment (Hahn and Mendgen 1997). Several of these genes encode transmembrane transporters for amino acids and carbohydrates in addition to a plasma membrane ATPase that was proposed to drive nutrient uptake (Hahn et al. 1997; Struck et al. 1998; Voegele et al. 2001). It was indicated that haustoria also have biosynthetic capacities (Sohn et al. 2000).

The host, too, must undergo changes in the expression of genes for amino acid and carbon metabolism, since "classical" physiological studies reported several changes in plants infected with rust fungi (Calonge 1970; Götz and Boyle 1998; Pandey et al. 1980; Reisener 1969; Srivastava et al. 1980; Tetlow and Farrar 1993). After an initial increase, photosynthesis was reduced, the concentration of sugars in the infected tissue increased, and the concentration of amino acids was differentially affected. Molecular data supporting these observations are not yet available. However, these molecular data are essential to better understand fungus-host interactions, since it has been almost impossible to distinguish between the contributions of host and parasite to the overall changes.

Here, we designed reverse-transcription-polymerase chain reaction (RT-PCR) assays for a variety of enzymes and transporters involved in amino acid and sugar metabolism to discriminate fungal from host activities. We provide the first molecular evidence for altered regulation of host genes encoding ATPase, an amino acid transporter, asparagine synthetase, and sucrose synthase after infection with a rust fungus. The results obtained reflect the capability of the fungus to extract sugars and amino acids from the host plant.

\section{RESULTS AND DISCUSSION}

The RT-PCR procedure employed allowed us to monitor gene expression of both partners in the $U$. fabae-V. faba pathosystem at high levels of sensitivity and specificity. We evaluated the quality of the procedure by analysis of transcripts of constitutively expressed genes on serial dilutions of RNA isolated from infected leaves (12 days postinoculation [dpi]). For the host, the gene $V f$-EFla encoding the translation elongation factor EF-1 alpha (Perlick and Pühler 1993) and, for the pathogen, the gene Uf-PMAl encoding plasma membrane ATPase (Struck et al. 1998) were used. In both cases, the detection limit was close to $1 \mathrm{ng}$ of total RNA (data not shown). The procedure employed was, therefore, much more 


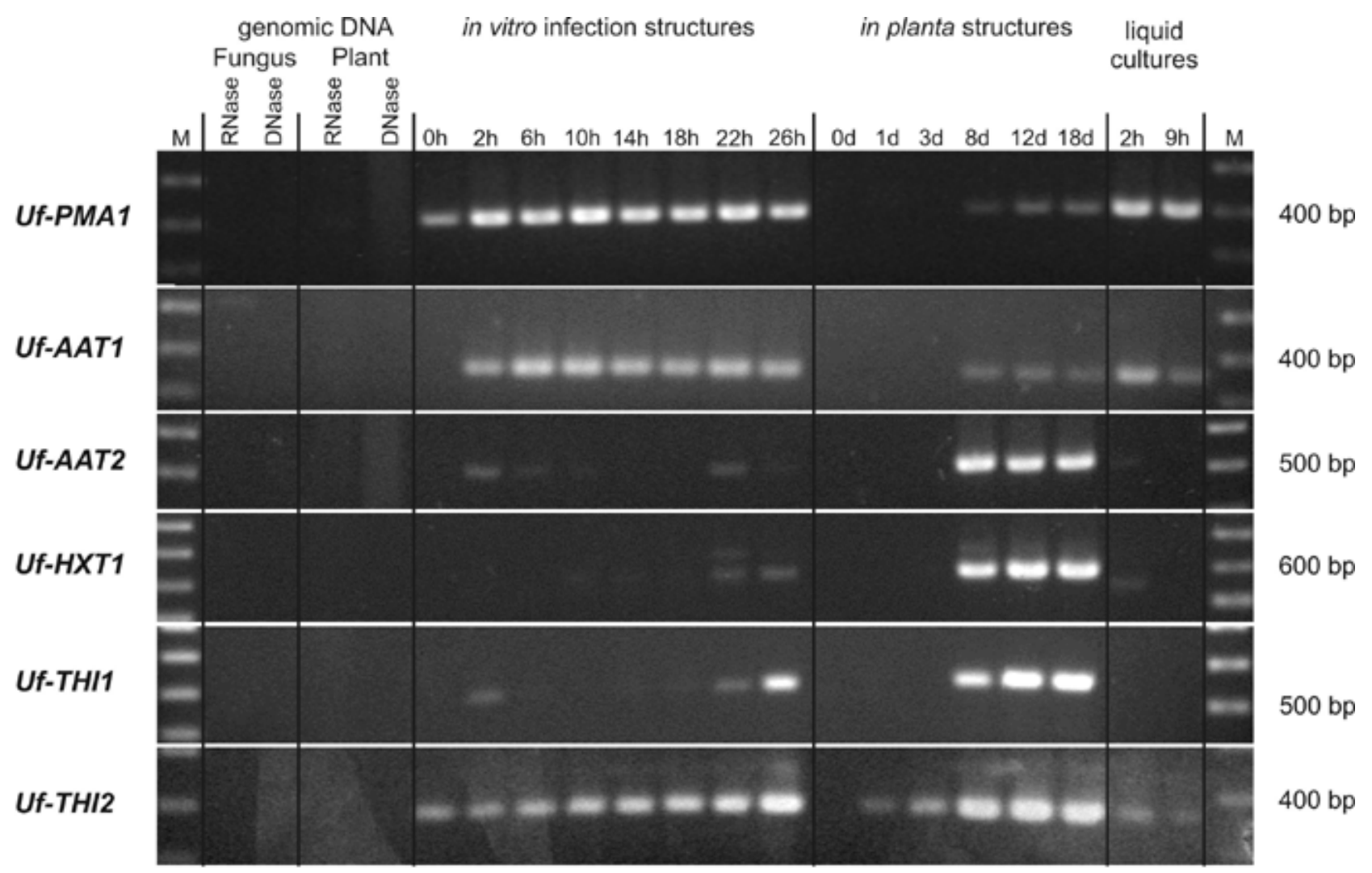

Fig. 1. Regulation of Uromyces fabae genes in vitro and in planta. Agarose gels showing reverse-transcription-polymerase chain reaction results for the indicated genes (Table 1). M: Molecular weight marker; genomic DNA: controls from U. fabae (fungus) and Vicia faba (plant), samples received treatment with DNase or RNase as indicated; in vitro infection structures: grown for the indicated period after inoculation (0h $=$ ungerminated spores); in planta structures: leaf samples various days after infection $(0 \mathrm{~d}=$ noninfected leaves); liquid cultures: undifferentiated germ tubes 2 and $9 \mathrm{~h}$ old. All RNA samples received a DNase treatment.

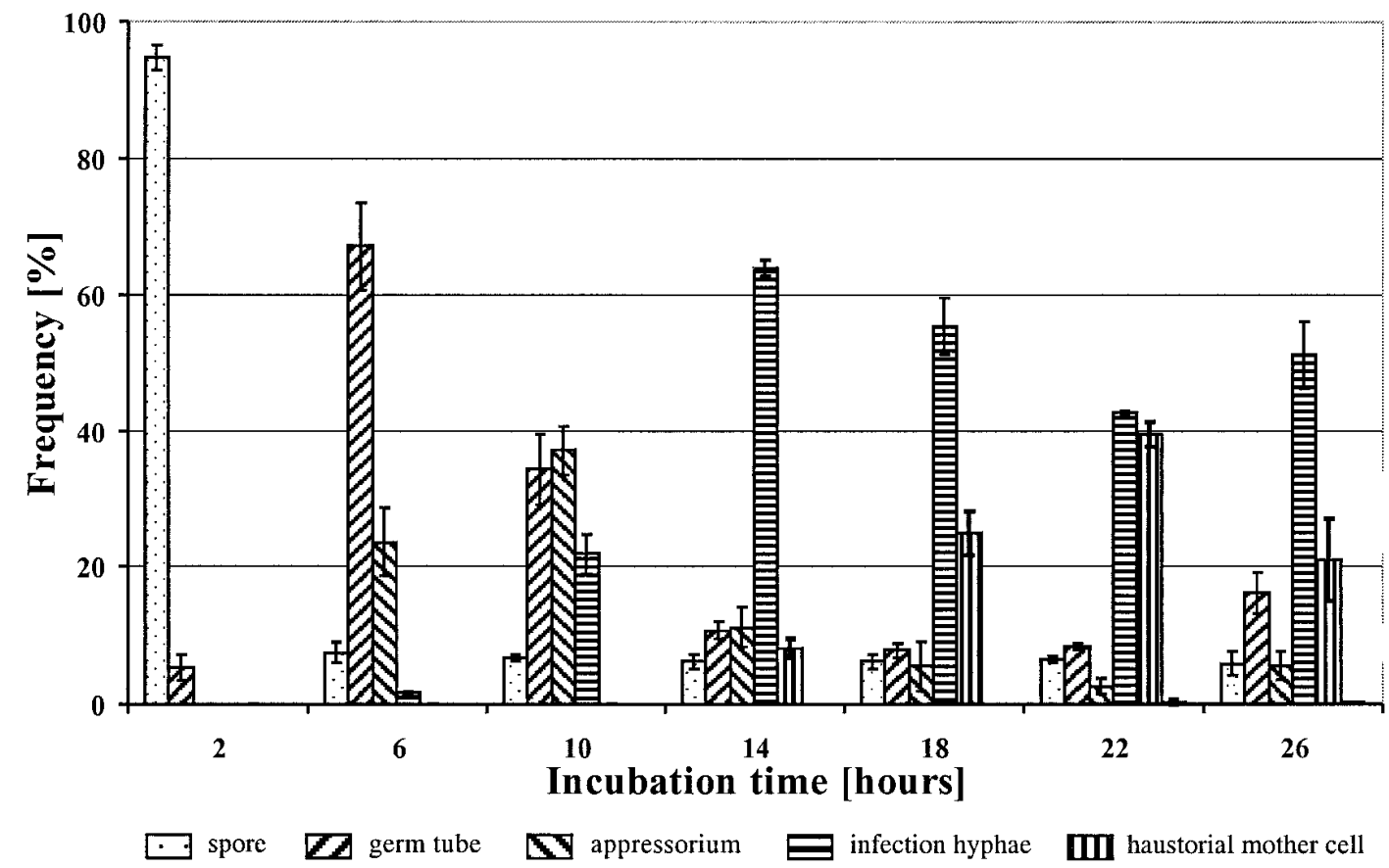

Fig. 2. Time-resolved differentiation of Uromyces fabae infection structures in vitro. The bar graph presents the percentage of a defined developmental stage at the time structures were collected. Abscises: incubation time; ordinate: percentage of respective cell types (spore, germ tube, appressorium, infection hyphae, and haustorial mother cell). 
sensitive than the RNA blot analysis used to quantify gene expression in those earlier studies.

Transcripts of the pathogen were analyzed in infected plants of various stages ( 1 to $18 \mathrm{dpi}$ ) and in vitro differentiated structures ( 2 to $26 \mathrm{~h}$ postinoculation [hpi]) (Fig. 1). The latter offers the opportunity to study early fungal gene expression without host background. Microscopy on samples from in vitro differentiated structures used for RNA preparation allowed the correlation of developmental stage with expression patterns (Fig. 2). As expected (Deising et al. 1991), formation of haustoria was negligible in this in vitro system. We used RNA preparations from three vegetative

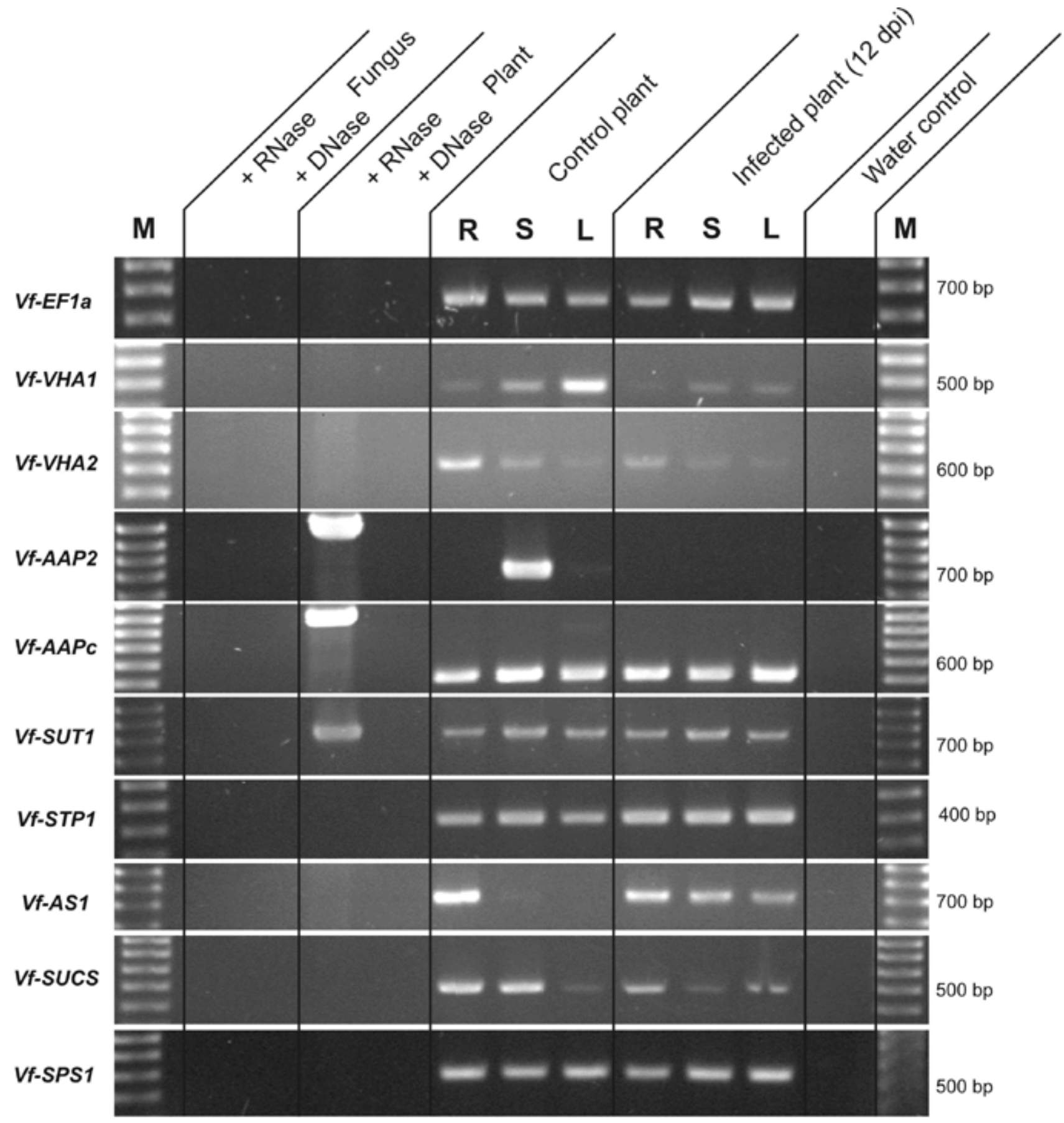

\section{Genomic DNA}

Fig. 3. Changes in host gene expression in response to Uromyces fabae infection (12 days postinoculation). Agarose gels showing reverse-transcriptionpolymerase chain reaction (RT-PCR) results for the indicated genes (Table 1). M: Molecular weight marker; R: root; S: stem; and L: leaf. All RT-PCR samples received a DNase treatment. Controls in lanes 2 to 5 were as in Figure 1. 
organs (leaf, stem, and root) originating from healthy and infected plants (12 dpi) to monitor host gene expression (Fig. 3 ). This study was focused on genes for amino acid and carbon metabolism, since older physiological data indicated corresponding dramatic changes during obligate biotrophic interactions (Pandey et al. 1980; Srivastava et al. 1980). Genes encoding plasma membrane ATPases were included because plant and fungal secondary transporters usually use protons as cosubstrate (Rentsch et al. 1998; Struck et al. 1998; Sze et al. 1999). A list of all genes analyzed is given in Table 1.

In $V . f a b a$, two genes encoding plasma membrane ATPase are currently known ( $V f$-VHAl and $V f$-VHA2). We confirmed their expression in all vegetative tissues and the dominance of $V f$-VHAl in leaves and of $V f$-VHA2 in roots (Hentzen et al. 1996). Both were generally down-regulated upon infection (Fig. 3). In situ hybridization experiments with leaf sections detected both transcripts only in mesophyll and guard cells (Hentzen et al. 1996). ATPase was suggested to control stomatal apertures in guard cells (Assmann et al. 1985), and in mesophyll cells, ATPase presumably drives uptake of metabolites from the apoplast (Sze et al. 1999). Lowered transcript levels of $V f$-VHAl in leaves might, therefore, reflect an attempt of the host to limit water loss by reducing stomatal openings. An earlier physiological work underlines this assumption, since it reported reduced transpiration rates and stomatal apertures in rust fungus infections before uredosori were fully developed (Tissera and Ayres 1986). It might also be possible that changed ATPase transcript levels in leaves reflect alterations of the proton gradient in mesophyll cells, which might be related to uptake activities of the mycelium. U. fabae most likely harbors only a single gene encoding such a proton pump (Uf-PMA1) (Struck et al. 1998). We found the corresponding transcripts during all developmental stages, includeing spores (Fig. 1). This suggests that $U f$-PMA1p is used throughout the mitotic uredospore cycle to create a proton gradient that cotransports nutrients into haustoria, but also other cell types (discussed below).

Next, we analyzed several transporters from the host and the pathogen that most likely depend on the proton gradient

Table 1. Genes analyzed by reverse-transcription-polymerase chain reaction (RT-PCR)

\begin{tabular}{lll}
\hline Target $^{\mathbf{a}}$ & \multicolumn{1}{c}{ Encoded function } & Accession no. \\
\hline$U f-P M A 1$ & Plasma membrane ATPase & AJ003067 \\
Uf-AAT1 & Amino acid transporter & In preparation \\
Uf-AAT2 & Amino acid transporter & U81794 \\
Uf-HXT1 & Hexose transporter & AJ310209 \\
Uf-THI1 & Pyrimidine precursor biosynthesis enzyme & AJ250426 \\
Uf-THI2 & Thiazole biosynthetic enzyme & AJ250427 \\
$V f-E F 1 a$ & Translational elongation factor & AJ222579 \\
$V f-V H A 1$ & Plasma membrane ATPase & S79323 \\
$V f-V H A 2$ & Plasma membrane ATPase & AB022442 \\
$V f-A A P 2$ & Amino acid transporter & Y09591 \\
$V f-A A P c$ & Amino acid transporter & AF061436 \\
$V f-S U T 1$ & Sucrose transporter & Z93774 \\
$V f-S T P 1$ & Hexose transporter & Z93775 \\
$V f-A S 1$ & Asparagine synthetase & Z72354 \\
$V f-S U C S$ & Sucrose synthase & X69773 \\
Vf-SPS1 & Sucrose phosphate synthase & Z56278 \\
\hline
\end{tabular}

${ }^{\mathrm{a}} U f=$ Uromyces fabae gene and $V f=$ Vicia faba gene. Results for $U f$ genes are shown in Figure 1 and those for $V f$ genes in Figure 3. generated by ATPases. From the four amino acid transporters reported for $V$. faba (Montamat et al. 1999), three were only partially characterized. The fourth, $V f-A A P 2$, was found to be mainly expressed in stems and, to a small extent, in leaves, but not in roots. These results were confirmed by our RT-PCR study (Fig. 3). However, transcripts of $V f-A A P 2$ were not detectable in any organ of infected plants under the conditions employed. $V f$-AAP2 has been characterized by uptake studies with transgenic yeast that revealed a relatively broad specificity for aromatic and neutral aliphatic amino acids (Montamat et al. 1999). Its closest homologue in Arabidopsis thaliana, AAP2, has been immunolocalized in the phloem of the stem and in veins supplying seeds (Hirner et al. 1998). Reduced transcript levels of $V f-A A P 2$ after infection might, therefore, indicate that the fungus influences its host to minimize loss of nutrients to competing sink organs. On the other hand, expression of $V f$ $A A P C$, the second host amino acid transporter analyzed, was little affected by fungal infection (Fig. 3). This apparent contradiction could be explained on the basis that the fungus only relies on a supply of certain amino acids provided by the host, whereas it is able to synthesize other amino acids itself. We do have some indirect evidence for this assumption. First, earlier physiological data indicated that rust fungi differentially alter amino acid composition in infected host tissues (Pandey et al. 1980; Srivastava et al. 1980). Second, data from an ongoing expressed sequence tag (EST) sequencing project suggest that genes from certain amino acid biosynthesis pathways are expressed in haustoria (K. W. Mendgen, U. Hempel, and M. Hahn, unpublished data). Regarding transporters for carbohydrates, $U$. fabae seems to have little influence on the host. Neither the sucrose transporter $V f-S U T 1$ nor the hexose transporter $V f$-STPl appeared to be affected in their constitutive expression by infection with $U$. fabae in infected tissue or at a distance.

With respect to uptake systems in $U$. fabae, we analyzed three permeases, two with homology to amino acid transporters $(U f-A A T 1$, formerly $U f$-PIG27, and $U f$-AAT2, formerly $U f$ PIG2) (Hahn and Mendgen 1997; Hahn et al. 1997) and one hexose transporter (Uf-HXT1) (Voegele et al. 2001). Uf-AAT1 showed expression during all developmental stages, whereas $U f$-AAT2 was weakly detectable in early and late infection structures but appeared repressed in between (Fig. 1). Additionally, the lack of expression in undifferentiated germ tubes grown in liquid cultures (Fig. 1, lanes 20 and 21) also indicated morphogenic control of $U f-A A T 2$. Substrate specificity is still unknown for $U f-A A T 1$ and $U f-A A T 2$, but the $U f-A A T 2$ gene product was localized exclusively in the periphery of haustoria (Hahn et al. 1997). This indicates that some amino acids might only be taken up by haustoria, others by various infection structures and secondary hyphae. Similar to $U f-A A T 2$, $U f-H X T 1$ only showed weakly detectable levels of transcript in late in vitro-grown infection structures, but high levels in leaves with haustoria (Fig. 1). The hexose transporter $U f-H X T 1$ is currently the only transporter biochemically characterized (Voegele et al. 2001). It has a clear preference for glucose and fructose as substrate and could be localized exclusively in the plasma membrane of haustoria.

In addition, we investigated transcript levels for a number of metabolic enzymes. On the host side, these were aspara- 
gine synthetase $(V f-A S 1)$, sucrose synthase $(V f-S U C S)$, and sucrose phosphate synthase (Vf-SPS1). Our RT-PCR analysis confirmed high levels of $V f$-ASI transcripts in roots, low levels in stems, and their absence in leaves of healthy plants (Küster et al. 1997). Plants infected by the rust fungus exhibited a strong up-regulation of $V f$-ASl transcript levels in stems and leaves (Fig. 3). Asparagine synthetase generates the long-distance transport form for reduced nitrogen in $V$. faba. We suggest that the altered regulation of $V f$-ASI in infected plants might be a sign for an enhanced flow of asparagine toward the fungal mycelium. This view is supported by an older physiological work that reported the depletion of especially asparagine and methionine in broad bean tissues infected with $U$. fabae (Srivastava et al. 1980). Asparagine's secondary amino group could be used for the synthesis of other amino acids that are not taken up from the host. In addition to the arguments discussed above, the dissimilar regulation of the two host amino acid carriers analyzed ( $V f-A A P 2$ and $V f-A A P c)$ might also justify this interpretation. Concerning sucrose synthase (Vf-SUCS) and sucrose phosphate synthase ( $V f$-SPS1), we observed a differential response to pathogen infection (Fig. 3). Only $V f$-SUCS appeared to be affected by rust fungus infection. We observed its down-regulation in roots and stems and its up-regulation in leaves, thus reflecting a shift in the source-sink balance of the pathosystem. The up-regulation in leaf mesophyll cells might be correlated with expression of the fungal hexose transporter. Sucrose synthase was recognized to be responsible for the conversion of sucrose to fructose and UDP-glucose rather than for the opposite reaction (Sturm and Tang 1999). It is cytoplasmically located, correlates with anabolic processes, and is an indicator of sink strength (Sturm and Tang 1999). Vf-SUCS had initially been investigated in the context of nodulation. There, it appeared to be moderately transcribed in uninfected roots and less in stems and leaves (Küster et al. 1993). A strong induction was observed in root nodules.

On the fungal side, we analyzed two genes for anabolic enzymes from the vitamin $B_{1}$ biosynthesis pathway (Sohn et al. 2000). Uf-THI1 transcripts appeared to be abundant in infected leaves with haustoria (Fig. 1). In RNA preparations from the in vitro differentiated fungus, $U f$-THII transcripts were barely detectable in early infection structures and easily detectable in late infection structures (Fig. 1). They were not discovered in undifferentiated germ tubes grown in liquid cultures (Fig. 1, lanes 20 and 21), additionally indicating a developmental control of gene expression. In contrast, $U f$-THI2 transcripts were detected not only in late infection structures but also in uredospores, early infection structures, and undifferentiated germ tubes, thus pointing to the absence of a strict morphogenic control (Fig. 1). Their continuous increase over time in in vitro-grown infection structures might indicate a type of regulation that also differs from that of constitutively expressed genes like $U f-P M A 1$, $U f$-AATl (Fig. 1), and $U f-T B B 1$ encoding beta-tubulin (data not shown). The analyses of Uf-THII and $U f$-THI2 presented here revealed dissimilar types of gene regulation instead of the rather similar results obtained by RNA blot analysis (Sohn et al. 2000). In this respect, it has to be considered that the method employed here operates at an increased sensitivity. In addition, here we used more time points, which revealed additional details of gene regulation not seen before.

At first sight, our current finding that some genes ( $U f-T H I$, $U f-A A T 1$, and $U f-H X T 1$ ) encoding proteins believed to be specific for haustoria are also detectable, although at low levels, in late infection structures from in vitro differentiated rust fungus might come as a surprise. We offer two explanations. On one hand, the few haustoria $(<0.1 \%)$ produced in the in vitro system might be sufficient to generate enough of the respective mRNA to be detectable by the highly sensitive RT-PCR protocol used here. It might also be possible that transcription of genes encoding haustorial proteins begins just before haustoria actually develop, i.e., in matured haustorial mother cells. Low amounts of these transcripts might be deposited in uredospores as well, since they were sometimes detectable very early, but completely diminished after a few hours. Therefore, our earlier statement that the regulation of these genes follows morphogenesis is still valid, since their transcription seems to be repressed until about $22 \mathrm{hpi}$. One line of future research might address the questions of why and how rust fungi down-regulate a subset of genes for this rather short period if one projects it on the whole uredospore multiplication cycle.

Taken together, we show for the first time that regulation of several host genes encoding enzymes and transporters participating in amino acid and carbon metabolism is altered by rust fungus infection. This is not restricted to infected leaves, but detectable in all vegetative organs. The altered host gene regulation might either be an indirect effect caused by shifted source-sink relationships or directly invoked by the activity of certain fungal gene products. These alternatives should be addressed in another line of future research.

\section{MATERIALS AND METHODS}

\section{Fungal and plant materials.}

Uredospores of $U$. fabae (Grev.) Fuckel were produced on V. faba cv. Con Amore as described (Deising et al. 1991). Plants were inoculated for RNA preparation as published (Hahn and Mendgen 1997). In vitro differentiated fungal infection structures were obtained in an aluminum box $(52.5 \times$ $31.5 \times 1 \mathrm{~cm}$ ) with a closely fitting lid holding a wet sheet of Whatman $3 \mathrm{MM}$ paper to provide for humidity. The bottom of the box was completely covered with a sheet of polyethylene (Bender \& Hobein GmbH, Ulm, Germany) and inoculated with $300 \mathrm{mg}$ of dry uredospores. Further manipulation was as described (Deising et al. 1991). Liquid cultures were used for control experiments to arrest uredospore differentiation in the germ tube stage (Struck et al. 1996).

\section{RNA isolation.}

At a given time after inoculation, the box was transferred to a cold room where small pieces $(1 \times 1 \mathrm{~cm})$ were cut from the polyethylene sheet and stained with lactophenol blue for evaluating cellular differentiation by microscopy. RNA isolation started by collecting fungal material from the sheet with a sterile razor blade. Cells were suspended in $0.9 \mathrm{ml}$ of RLT buffer provided with the RNeasy Plant Mini Kit (Qiagen $\mathrm{GmbH}$, Hilden, Germany) and disrupted on ice by two 60 -s bursts with a rotor-stator homogenizer (IKA Ultra Turrax, 
model S8N-8g; Bender \& Hobein GmbH). Further steps followed the protocol provided with the kit. Final elution was performed with $100 \mu \mathrm{l}$ of water. This method typically resulted in up to $100 \mu \mathrm{g}$ of high quality RNA. Preparation of RNA from plant tissues relied essentially on the same procedure. Pieces of the respective plant organ (100 to $200 \mathrm{mg}$ ) were transferred to $13-\mathrm{ml}$ plastic tubes that were immediately frozen in liquid nitrogen. Adherent soil had been removed from roots under running tap water prior to freezing. The samples were covered with liquid nitrogen, crunched with a sterile spatula, and then put on ice. After adding $1.8 \mathrm{ml}$ of RLT buffer, further processing was as above. Quantity and quality controls of RNA preparations included UV spectrophotometry and gel electrophoresis (data not shown). For the latter, $500 \mathrm{ng}$ of RNA was analyzed on an 1\% agarose$0.5 \mathrm{M}$ formaldehyde gel as described (Brown 1994) and digitally recorded. Relative intensities of rRNA bands were calculated with the Multi Analyst version 1.0.2 software implemented on the Gel Doc 1000 UV-system (BioRad GmbH, München, Germany). All preparations used for RT-PCR experiments showed distinct rRNA bands with only minor variation in relative intensities.

\section{Primer design for RT-PCR.}

Primer sequences and specifications for RT-PCR are detailed in Table 2. For host genes, we relied on sequences deposited in the EMBL/GenBank databases; for the pathogen, we used sequences derived from our own projects. Since cDNA as well as genomic DNA sequences were available for all fungal genes analyzed here, primers were designed so that they always resided on different exons. Amplification products generated from putatively contaminating genomic DNA would, therefore, be distinguishable from those generated from RNA templates. On the other hand, for all plant genes, only cDNA sequences were available. In order to eliminate putative artifacts resulting from amplification of genomic DNA in these cases, we also implemented a DNase treatment into the procedure as outlined below.

Primers were designed with the software module PrimerSelect that is part of the DNAStar package (GATC Biotech
AG, Konstanz, Germany). Primers were derived to produce RT-PCR products that were in the range of 350 to $750 \mathrm{bp}$ and allowed annealing at about 55 to $60^{\circ} \mathrm{C}$. In a few cases, we used higher annealing temperatures to increase the specificity of the reaction as indicated in Table 2 . In cases in which several genes with corresponding functions were analyzed (Table 1), e.g., amino acid transporters, we aligned those sequences with the DNAStar package software module MegAlign. Primers that resided in divergent regions of those genes were selected.

\section{RT-PCR.}

The Titan One Tube RT-PCR kit (Roche GmbH, Mannheim, Germany) is designed as a one-step-one-tube system in which first-strand cDNA synthesis relies on one of the genespecific primers used for the amplification step. cDNA synthesis and PCR are coupled to a continuous procedure in which all components are included in a single tube before the first step. We employed a modification of this procedure in order to integrate a DNase treatment without having to change the buffer system (Huang et al. 1996). This ensured that amplified bands originated from RNA, and not DNA, templates. We also implemented a touchdown protocol, since it increases specificity (Don et al. 1991).

The reaction volume was scaled down to a final total of $12.5 \mu \mathrm{l}$. A single standard reaction included $50 \mathrm{ng}$ of total RNA and a mix of $2.5 \mu \mathrm{l}$ of $5 \times$ RT-PCR buffer (Roche $\mathrm{GmbH}$, Mannheim, Germany), $7 \mathrm{U}$ of rRNasin (Promega $\mathrm{GmbH}$, Mannheim, Germany), 0.7 U of RQ DNase (Promega GmbH), and $2 \mathrm{mM}$ dithiothreitol (DTT) (Roche $\mathrm{GmbH}$ ). The final volume of this DNase reaction was $7 \mu \mathrm{l}$. One set of controls contained $50 \mathrm{ng}$ of genomic DNA as template; others replaced rRNasin and RQ DNase with $1.4 \mathrm{U}$ of an RNase-cocktail (RNace It; Promega $\mathrm{GmbH}$ ). Incubation was for $30 \mathrm{~min}$ at $37^{\circ} \mathrm{C}$, followed by $75^{\circ} \mathrm{C}$ for $10 \mathrm{~min}$ to denature the DNase (Huang et al. 1996). A mix was added that increased the volume to $12.5 \mu \mathrm{l}$ and adjusted for $0.2 \mathrm{mM}$ dNTPs (MBI Fermentas $\mathrm{GmbH}$, St. Leon-Rot, Germany), $0.4 \mu \mathrm{M}$ gene-specific forward and reverse primers (MWG-Biotech GmbH, Ebersberg, Germany), 0.5 additional units of rRNasin, $5 \mathrm{mM}$ DTT, $0.5 \mu \mathrm{g}$

Table 2. Primers used for reverse-transcription-polymerase chain reaction (RT-PCR)

\begin{tabular}{|c|c|c|c|}
\hline Target $^{a}$ & Conditions $^{\mathrm{b}}$ & Forward primer sequence $\left(5^{\prime}\right.$ to $\left.3^{\prime}\right)$ & Reverse primer sequence $\left(5^{\prime}\right.$ to $\left.3^{\prime}\right)$ \\
\hline Uf-PMAl & Cyc: 30 & ATTTGTGTGCAATGACTGG & GATGGCGTATGTGAAAATCT \\
\hline Uf-AAT1 & Ann: $15 \mathrm{~s}$; Syn: $15 \mathrm{~s}$ & AGTGGCTCGCAAATTTCTCTTCTG & CGAATTCGCGTTTTCCCGTTAC \\
\hline Uf-AAT2 & Standard & TGCCGCCACCATTGTCGTAG & CATCGCCGGTGCTTCCTAAAAG \\
\hline Uf-HXT1 & Ann: $62^{\circ} \mathrm{C}$ & GTCGCGATTGTCATTGCTGTATTTG & TCTCGGCGATTCGGGTAACAC \\
\hline Uf-THII & Standard & ATCCTTGAACCGAATGACC & CTCATGAAGGCAGCGGTCTCC \\
\hline Uf-THI2 & Standard & AAGAATGTCTCCCGTTGCTACTGA & CACCACCGGGAGCGACATTAC \\
\hline$V f-E F 1 a$ & Standard & TTAAGGCTGAGCGTGAAAGAGG & TCAAACCGGTAGGAGCAAAAGTC \\
\hline$V f$-VHA1 & Ann: $65^{\circ} \mathrm{C} / 15 \mathrm{~s} ;$ Syn: $10 \mathrm{~s}$ & CCGAGCAGGCCAAGAGACG & GCCGCCAAGTTTCCCAATAGG \\
\hline$V f-V H A 2$ & Ann: $15 \mathrm{~s}$ & AACGCCCTGGAGCCCTAT & GGCCTCCTCTTTGACTTTTATTG \\
\hline$V f-A A P 2$ & Standard & GGCTCGGGAGTTCTTTCGTTGTC & TGGCCTTTTTCATGGTCTTGTGC \\
\hline$V f-A A P c$ & Ann: $62^{\circ} \mathrm{C}$ & TGTTGCGCAATTGTTACTTATGTTT & CGGCACGATTAGCAGGTTCTA \\
\hline Vf-SUT1 & Standard & GCCGGTAACCAACGCAAAACG & GCGCCGGCCTTGATACCTTC \\
\hline$V f-S T P 1$ & Standard & CTGGCCGCGCTTTTGTCG & ATTTGGCGTGTCGGGTAGGATTAG \\
\hline$V f-A S$ & Standard & GTGCCTTTCGGTGTTTTACTATCG & CCAGCCATATCCAАСТССАТСАС \\
\hline Vf-SUCS & Standard & TCGTCCAAGGCCAGGTGTTTG & GCTCTGCGCTGTCTCCCCAAC \\
\hline$V f-S P S 1$ & Cyc: 30 & GTCTGGCCGGTTGCTATTCACG & CTGGCCTGGCAAGAGCGAGTATC \\
\hline
\end{tabular}

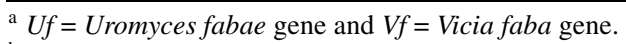

${ }^{\mathrm{b}}$ Changes from standard conditions were as indicated: 'Ann' refers to the final annealing conditions of the first PCR block and all cycles of the second PCR block, 'Syn' refers to the synthesis steps of all cycles of the first PCR block and the first cycle of the second PCR block, and 'Cyc' refers to the number of cycles of the second PCR block. 
of bovine serum albumine per $\mu$ (Fluka GmbH, Neu-Ulm, Germany), and $0.02 \mu \mathrm{l}$ of Titan enzyme mix per $\mu$ of the reaction. The final concentration of $\mathrm{MgCl}_{2}$ was $1.5 \mathrm{mM}$. Reactions were overlaid with $20 \mu \mathrm{l}$ of mineral oil and placed into a MiniCycler (MJ Research, Inc., Watertown, MA, U.S.A.) programmed for continuous RT-PCR. cDNA synthesis was at $55^{\circ} \mathrm{C}$ for $30 \mathrm{~min}$, followed by a single step at $94^{\circ} \mathrm{C}$ for $3 \mathrm{~min}$ and 10 cycles of a touchdown PCR protocol: $94^{\circ} \mathrm{C}$ for $30 \mathrm{~s}$, $70^{\circ} \mathrm{C}$ for $30 \mathrm{~s}$ with a decrease of $1{ }^{\circ} \mathrm{C}$ per cycle, and $72^{\circ} \mathrm{C}$ for $30 \mathrm{~s}$. This was immediately followed by 35 cycles of the subsequent protocol: $94^{\circ} \mathrm{C}$ for $30 \mathrm{~s}, 60^{\circ} \mathrm{C}$ for $30 \mathrm{~s}$, and $72^{\circ} \mathrm{C}$ for $30 \mathrm{~s}$ plus one additional second per cycle. Reactions were cooled to $2^{\circ} \mathrm{C}$ after a final extension at $72^{\circ} \mathrm{C}$ for $10 \mathrm{~min}$. In instances in which these standard conditions did not produce satisfying results, programming was adjusted as indicated in Table 2. Reactions were completely loaded onto $2 \%$ agarose gels for analysis. After electrophoresis for $1 \mathrm{~h}$ at $100 \mathrm{~V}$, the gels were stained with ethidium bromide $(1 \mu \mathrm{g} / \mathrm{ml})$ and digitally recorded.

All assays were performed at least three times and always included controls to monitor the effectiveness of the DNase step. Controls shown in Figures 1 and 3 in lanes 2 to 5 used genomic DNA preparations from the fungus (lanes 2 and 3 ) and the host (lanes 4 and 5) that were either treated with RNase (lanes 2 and 4) or DNase (lanes 3 and 5). There was never any PCR product with fungal templates when using primers directed against plant genes and vice versa. In cases with bands in lanes 2 or 4, DNase treatment prevented their appearance in lanes 3 or 5 , respectively, thus demonstrating that the bands in the remaining reactions must have resulted from amplifications of RNA templates. This is exemplified for $V f-S U T 1$, a gene that apparently has no introns in the region amplified. Without the DNase treatment, bands in the RT-PCR would not be identifiable as amplification products originating from RNA or from contaminating DNA templates. The lack of PCR products in lanes of control reactions using genomic DNA after RNase treatment (Figs. 1 and 3, lanes 2 and 4 ) is due to one of two causes. In some cases, there was a PCR product that was considerably larger than that obtained with RNA templates due to the presence of introns and, therefore, shifted out of the section of the gels shown in the figures. In other cases, the primers were designed to cross intron/exon borders, thus preventing amplification of chromosomal DNA.

\section{ACKNOWLEDGMENTS}

We would like to thank our colleagues C. Struck and M. Hahn for discussions. This work was supported by the Deutsche Forschungsgemeinschaft through grant no. Me 523/24-1 and by the Fonds der Chemischen Industrie.

\section{LITERATURE CITED}

Assmann, S. M., Simoncini, L., and Schroeder, J. I. 1985. Blue light activates electrogenic ion pumping in guard cell protoplasts of Vicia faba. Nature 318:285-287.

Brown, T. 1994. Analysis of RNA by Northern and slot blot hybridization. Pages 4.9.2-4.9.4 in: Current Protocols in Molecular Biology. F. M. Ausubel, R. Brent, R. E. Kingston, D. D. Moore, J. G. Seidman, J. A. Smith, and K. Struhl, eds. Wiley Interscience, New York

Calonge, F. D. 1970. Qualitative determination of amino acids and free sugars in healthy and rust infected barley leaves. Microbiol. Esp. 23: 195-201.

Deising, H., Jungblut, P. R., and Mendgen, K. 1991. Differentiationrelated proteins of the broad bean rust fungus Uromyces viciae-fabae as revealed by high resolution two-dimensional polyacrylamide gel electrophoresis. Arch. Microbiol. 155:191-198.

Don, R. H., Cox, P. T., Wainwright, B. J., Baker, K., and Mattick, J. S. 1991. Touchdown PCR to circumvent spurious priming during gene amplification. Nucleic Acids Res. 19:4008.

Götz, M., and Boyle, C. 1998. Changes in metabolite pools in host and pathogen during the uredinio and teliospore development of the bean rust fungus Uromyces appendiculatus. J. Phytopathol. 146: 599-607.

Hahn, M., and Mendgen, K. 1997. Characterization of in planta-induced rust genes isolated from a haustorium-specific cDNA library. Mol. Plant-Microbe Interact. 10:427-437.

Hahn, M., Neef, U., Struck, C., Göttfert, M., and Mendgen, K. 1997. A putative amino acid transporter is specifically expressed in haustoria of the rust fungus Uromyces fabae. Mol. Plant-Microbe Interact. 10: 438-445.

Hentzen, A. E., Smart, L. B., Wimmers, L. E., Fang, H. H., Schroeder, J. I., and Bennett, A. B. 1996. Two plasma membrane H(+)-ATPase genes expressed in guard cells of Vicia faba are also expressed throughout the plant. Plant Cell Physiol. 37:650-659.

Hirner, B., Fischer, W. N., Rentsch, D., Kwart, M., and Frommer, W. B. 1998. Developmental control of H+/amino acid permease gene expression during seed development of Arabidopsis. Plant J. 14: 535-544.

Huang, Z., Fasco, M. J., and Kaminsky, L. S. 1996. Optimization of DNase I removal of contaminating DNA from RNA for use in quantitative RNA-PCR. Biotechniques 20:1012-1020.

Küster, H., Frühling, M., Perlick, A. M., and Pühler, A. 1993. The sucrose synthase gene is predominantly expressed in the root nodule tissue of Vicia faba. Mol. Plant-Microbe Interact. 6:507-514.

Küster, H., Albus, U., Frühling, M., Tchetkova, S. A., Tikhonovitch, I. A., Pühler, A., and Perlick, A. M. 1997. The asparagine synthetase gene VfAS1 is strongly expressed in the nitrogen-fixing zone of broad bean (Vicia faba L.) root nodules. Plant Sci. 124:89-95.

Montamat, F., Maurousset, L., Tegeder, M., Frommer, W., and Delrot, S. 1999. Cloning and expression of amino acid transporters from broad bean. Plant Mol. Biol. 41:259-268.

Pandey, P. K., Prasad, M., and Bhushan, A. 1980. Changes in the composition of free amino acids and sugars of leaf sheath and culm of wheat during uredospore and teleutospore formation of Puccinia graminis tritici. Zentralbl. Bakteriol. Naturwiss. 135:339-343.

Perlick, A. M., and Pühler, A. 1993. A survey of transcripts expressed specifically in root nodules of broadbean (Vicia faba L.). Plant Mol. Biol. 22:957-970.

Reisener, H. J. 1969. The metabolism of alanin, glycine and arginine in uredospores of Puccinia graminis var. tritici during germination. Arch. Mikrobiol. 69:101-113.

Rentsch, D., Boorer, K. J., and Frommer, W. B. 1998. Structure and function of plasma membrane amino acid, oligopeptide and sucrose transporters from higher plants. J. Membr. Biol. 162:177-190.

Sohn, J., Voegele, R. T., Mendgen, K., and Hahn, M. 2000. High level activation of vitamin B1 biosynthesis genes in haustoria of the rust fungus Uromyces fabae. Mol. Plant-Microbe Interact. 13: 629-636.

Srivastava, K. K., Sinha, R. K., Pandey, P. K., and Prasad, M. 1980. Variations in amino acids and sugars in different tissues of broad bean (Vicia faba L.) during the pathogenesis of Uromyces fabae (Pers.) de Bary. Zentralbl. Bakteriol. Naturwiss. 135:344-350.

Struck, C., Hahn, M., and Mendgen, K. 1996. Plasma membrane H+ATPase activity in spores, germ tubes and haustoria of the rust fungus Uromyces viciae-fabae. Fung. Gen. Biol. 20:30-35.

Struck, C., Siebels, C., Rommel, O., Wernitz, M., and Hahn, M. 1998. The plasma membrane $\mathrm{H}^{+}$-ATPase from the biotrophic rust fungus Uromyces fabae: Molecular characterization of the gene (PMA1) and functional expression of the enzyme in yeast. Mol. Plant-Microbe Interact. 11:458-465.

Sturm, A., and Tang, G. Q. 1999. The sucrose-cleaving enzymes of plants are crucial for development, growth and carbon partitioning. Trends Plant Sci. 4:401-407.

Sze, H., Li, X., and Palmgren, M. G. 1999. Energization of plant cell 
membranes by H+-pumping ATPases. Regulation and biosynthesis. Plant Cell 11:677-690.

Tetlow, I. J., and Farrar, J. F. 1993. Apoplastic sugar concentration and $\mathrm{pH}$ in barley leaves infected with brown rust. J. Exp. Bot. 44: 929-936.

Tissera, P., and Ayres, P. G. 1986. Transpiration and the water relations of faba bean (Vicia faba) infected by rust (Uromyces viciae-fabae). New Phytol. 102:385-395.

Voegele, R. T., Struck, C., Hahn, M., and Mendgen, K. 2001. The role of haustoria in sugar supply during infection of broad bean by the rust fungus Uromyces fabae. Proc. Natl. Acad. Sci. U.S.A. 98:81338138 . 